\title{
GROWTH PERFORMANCE, BLOOD PARAMETERS AND INTESTINAL MORPHOLOGY OF MOLAR DUCKLINGS FED DIETS SUPPLEMENTED WITH PROBIOTICS
}

\author{
Manal K. Abou-Elnaga ${ }^{1}$; A. M. H. Abou-Ashour ${ }^{1}$; S. A. A. Abd El-Rahman ${ }^{1}$ and A.G. \\ Bayomi $^{2}$ \\ ${ }^{1}$ Poultry and Fish Production Department, Faculty of Agriculture, Menoufia University, Shebin El-Kom, \\ Egypt. \\ ${ }^{2}$ Post graduate (M. Sc.).
}

(Received 6/11/2018, accepted 17/12/2018)

\section{SUMMARY}

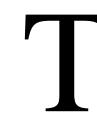

The present study was conducted to investigate the effect of feeding commercial probiotic preparation (Proact) supplementation on growth performance, carcass traits, blood parameters, intestinal morphological parameters and economical efficiency. A total of 240, one-day old Molar ducklings were individually weighed, wingbanded and randomly assigned to eight equal groups each of 3 replicates (30 birds each). All birds were fed a starter diet until 21- day of age and finisher diet from 22 day until marketing (70 d). Ducklings of group 1 (control) were fed the starter and finisher diets without Proact supplementation. Ducklings of groups 2, 3, 4, 5, 6, 7 and 8 were fed the control diets plus graded levels of Proact $(0.25,0.50,0.75,1.00,1.25,1.50$ and $1.75 \mathrm{~g} / \mathrm{kg}$ diet, respectively). Results revealed that ducklings of group $4(0.75)$ showed significantly $(\mathrm{P} \leq 0.05)$ higher body weight, body weight gain, feed intake and performance index. Moreover, feed conversion ratio, European efficiency index and economic efficiency were significantly improved. Carcass and giblets weights and percentage were significantly $(\mathrm{P} \leq 0.05)$ increased with the supplementation. Probiotics supplementation $(0.75 \mathrm{~g} / \mathrm{kg}$ diet $)$ significantly increased serum glucose and liver enzymes (AST and ALT), and significantly $(\mathrm{P} \leq 0.05)$ decreased createnine, cholesterol, triglyceride and total lipids. However; total protein and albumen were not affected. Moreover, villi height, villi width and villi height: villi width ratio were significantly improved by the addition of probiotics up to $0.75 \mathrm{~g} / \mathrm{kg}$ diet. Therefore, it may be concluded that supplementation of $0.75 \mathrm{~g}$ probiotics/ $\mathrm{kg}$ diet could be used in diets of Molar ducklings from 0-10 weeks of age to improve growth performance, feed efficiency, and carcass traits.

Keywords: probiotics, ducklings, performance, carcass, blood parameters, intestinal morphology.

\section{INTRODUCTION}

The primary role of a diet is not only to provide enough nutrients to fulfill metabolic requirements of the body, but also to modulate various functions of the body. Probiotics, prebiotics, and synbiotic are either beneficial microorganisms or substrates that facilitate the growth of these microorganisms, which can be suitably harnessed (Awad et al., 2009).

Probiotics are defined as live microbial food supplements which beneficially affect the host by improving its intestinal microbial balance. Furthermore, lactic acid bacteria are important aflatoxin reducer microorganisms, as has been emphasized by Hernandez- Mendoza et al., (2009).

Functional supplements, such as probiotics, regulate gut microbiota (Hemarajata and Versalovic, 2012) and improve performance (Peng et al., 2016). Improvement in growth performance and feed efficiency of broiler chickens fed probiotics is thought to be induced by the total effects of probiotic action including the maintenance of beneficial microbial population, improving feed intake and digestion and altering bacterial metabolism (Mountzouris et al., 2007).

In broiler nutrition, probiotic species belonging to Lactobacillus, Streptococcus, Bacillus, Bifidobacterium, Enterococcus, Aspergillus, Candida, and Saccharomyces have a beneficial effect on broiler 
performance (Kabir et al., 2004), modulation of intestinal microflora and pathogen inhibition (Pascual et al. 1999), and immunomodulation (Koenen et al., 2004).

Therefore, the aim of this study was to evaluate the efficiency of feeding graded levels of probiotic product (Proact) on duckling's performance, blood parameters and intestinal morphological parameters.

\section{MATERIALS AND METHODS}

The present study was conducted at a private farm in Sadat City, Menoufia governorate, Egypt, throughout the experimental period from July to September 2018.

A total of 240, one-day old Molar ducklings (obtained from Mesangere Company for ducks), were individually weighed, wing- banded and randomly assigned to eight equal groups nearly similar in average body weight (each of 3 replicates of 30 birds each), period (70 days). Artificial light was used to provide 24 hour photo period. All birds were fed starter diet until 21- day of age and finisher diet from 22 day until marketing (Table 1). Proact was purchased from Zeus Biotech Limited, India, and sale from Delta Vet Center for animal feeding, Egypt.

Table (1): Composition and calculated analysis of the experimental diets fed during starting (1 - 21) and finishing periods $(22$ - 70) days of age.

\begin{tabular}{|c|c|c|}
\hline Ingredient & Starter diet & Finisher diet \\
\hline Yellow corn, $8.5 \%$. & 64.45 & 70.20 \\
\hline Soybean meal, $48 \%$. & 30.90 & 25.60 \\
\hline Vegetable oil. & 0.60 & 0.50 \\
\hline Mono-calcium phosphate. & 1.60 & 1.50 \\
\hline Limestone, ground. & 1.70 & 1.50 \\
\hline Vitamins and minerals mixture ${ }^{1}$. & 0.30 & 0.30 \\
\hline Salt (Sodium chloride). & 0.30 & 0.30 \\
\hline DL- Methionine $^{2}$ & 0.15 & 0.10 \\
\hline Total & 100 & 100 \\
\hline \multicolumn{3}{|l|}{ Calculated analysis ( air dry basis) ${ }^{3}$ : } \\
\hline Crude protein, $\%$. & 20 & 18 \\
\hline ME, $\mathrm{k} \mathrm{cal} / \mathrm{kg}$ diet. & 2904 & 2970 \\
\hline $\mathrm{C} / \mathrm{P}$ ratio. & 145 & 165 \\
\hline Calcium, $\%$. & 1.00 & 0.90 \\
\hline Available phosphorous, $\%$. & 0.48 & 0.45 \\
\hline
\end{tabular}

Proact is a unique probiotic combination of spore forming lactic acid, which contains Bacillus subtilis: $1.75 \times 10^{12} \mathrm{CFU}$, Bacillus lichenifomis: $1.75 \times 10^{12} \mathrm{CFU}$ and total viable count: $3.5 \times 10^{12} \mathrm{CFU} / \mathrm{g}$, and dextrose monohydrate as a carrier up to $1 \mathrm{~kg}$. Ducklings of group 1 (control) was fed the starter and finisher diets that did not supplemented with Proact. Ducklings of groups 2, 3, 4, 5, 6, 7 and 8 were fed the control diets plus graded levels of Proact as follows: $0.25,0.50,0.75,1.00,1.25,1.50$ and $1.75 \mathrm{~g} / \mathrm{kg} \mathrm{diet}$, respectively. Diets were formulated to provide the recommended requirements according to the NRC (1994).

Body weight (BW), feed intake (FI) and mortality were recorded weekly. Body weight gain (BWG) and feed conversion ratio (FCR, g feed /g gain) were calculated every week during the experimental period. Performance index (PI) was calculated according to North (1981). Where: PI = live body weight, $\mathrm{kg} \times 100 /$ feed conversion ratio. European efficiency index (EEI) was calculated also as cited by Soltan and Kusainova (2012). 
Where: $\mathrm{EEI}=($ Mean BW, $\mathrm{kg} \times$ Livability, \% $) /($ Marketing age, days $\times \mathrm{FCR}) \times 100$.

At the end of the experiment (10 weeks of age ), 6 birds from each treatment around the average live body weight were randomly chosen, fasted for about 12 hours, weighed and slaughtered to complete bleeding, followed by plucking the feathers. Carcass without and with giblets (liver, heart and gizzard) weights were recorded and calculated relative to live body weight as follows:

$$
\text { Dressed \%= (carcass wt. + giblets wt.)/ LBW x } 100 .
$$

The small intestines of ducklings were removed immediately after slaughtering at 70 days age and segments of approximately $2 \mathrm{~cm}$ were taken from duodenum, jejunum and ileum for histological analysis. Segments referred to the midpoint of the duodenum (from gizzard to pancreo-biliary duct, duodenum), jejunum (the midpoint between the entry of the common bile duct and the Meckel's diverticulum), and ileum (from Meckel's diverticulum to ileocecal junction). Particular segments were gently flushed and rinsed with $0.9 \%$ physiological saline and then fixed in a $4 \%$ neutral-buffered formalin solution for histological study.

At slaughtering, individual blood samples were collected into tubes without heparin and serum was separated by centrifugation at $3000 \mathrm{rpm}$ for 15 minutes and frozen at $-20{ }^{\circ} \mathrm{C}$ until analysis. Serum total protein, triglyceride, lipids, cholesterol, createnine, glucose and albumin were determined using commercial kits. Also, liver enzymes including aspartate transaminase (AST) and alanine transaminase (ALT) were calorimetrically estimated. The economic efficiency of the experimental diets used in the present study was calculated from the input - output analysis (Heady and Jensen, 1954), assuming that the other head costs were constant.

Data were subjected to one way ANOVA by the completely randomized design using SPSS (2011) program, and the differences among means were determined using Duncan's multiple range test (Duncan, 1955). Percentages were transformed to the corresponding arcsine values before performing statistical analysis (Snedecor and Cochran, 1982). The model applied was:

$$
\mathrm{Yij}=\mu+\alpha \mathrm{i}+\mathrm{Eij}
$$

Where:- Yij= an observation. $\mu=$ Overall mean. $\alpha \mathrm{i}=$ effect of treatment $(\mathrm{I}=1,2,3,4, \ldots . .8)$, and $\mathrm{Eij}=$ Random error.

\section{RESULTS AND DISCUSSION}

\section{Body weight and body weight gain:}

The effect of dietary graded levels of probiotics supplementation on growth performance and performance index (PI) of white Molar ducklings at 3 and 10 weeks of age is presented in Table (2). Results indicate that at 3 weeks of age, there are significant differences among probiotic levels. Ducklings fed $1 \mathrm{~g}$ Proact/ kg diet showed significantly $(\mathrm{P} \leq 0.05)$ higher body weight $(1043 \mathrm{~g})$ followed by those fed $0.75,0.50$ and $1.25 \mathrm{~g} / \mathrm{kg}$ diet $(1034,1011$ and $1016 \mathrm{~g}$, respectively) as compared to $880 \mathrm{~g}$ for the control group. The same trend was noticed at the marketing age (70 days). Groups fed the diets supplemented with $0.75,1.00$ and $0.50 \mathrm{~g}$ probiotic / $\mathrm{kg}$ diet have significantly the heaviest BW $(4312,4191$ and $4178 \mathrm{~g}$, respectively) which is more than the control group $(3546 \mathrm{~g})$ by about $21.60,18.19$ and $17.82 \%$.

The average daily weight gain from $0-3$ and $0-10$ wks of groups fed Proact showed higher daily weight gain specially for chicks fed levels of 0.75 and $1.00 \mathrm{~g}$ Proact / kg diet compared to the control group and the other supplemented groups (Table 2).

Furthermore, the same trend was noted in performance index (for the 0 - 3 and $0-10$ wks periods) where ducklings fed Proact at levels of 0.75 and $1.00 \mathrm{~g} / \mathrm{kg}$ diet exhibited the best performance index compared to the control group being (53.02 and 57.16\%) and (141.46 and $130.24 \%$ ), respectively in comparison with 40.90 and $106.48 \%$ for the control group at the same periods.

These results are in agreement with the results of Alkhlaf et al. (2010) and Thomas et al. (2015) who reported that probiotic supplementation improved body weight and daily weight gain.

In contrast, Mohan et al. (1996) found that the beneficial effect of probiotic on chicken occurred only after the $4^{\text {th }}$ week of age. Also, Hassan et al. (2015) noted that inclusion of $0.1 \%$ Saccharomyces cerevisiae 
to 12,14 or $16 \%$ protein diet had no effect on BW until the $4^{\text {th }}$ week of feeding; however, it began to increase significantly $(\mathrm{P} \leq 0.05)$ from the $5^{\text {th }}$ week until the end of the experiment compared to the control group.

Table (2): Effect of dietary graded levels of Proact supplementation on growth performance and performance index of Molar ducks at 3 and 10 weeks of age (Means \pm S.E).

\begin{tabular}{|c|c|c|c|c|c|c|}
\hline \multirow{2}{*}{ Treatment $^{1}$} & \multicolumn{2}{|c|}{ Body weight (g ) } & \multicolumn{2}{|c|}{ Body weight gain/ d (g ) } & \multicolumn{2}{|c|}{ Performance Index (PI, \%) } \\
\hline & 3 weeks & 10 weeks & 3 weeks & 10 weeks & 3 weeks & 10 weeks \\
\hline $\mathrm{T}_{1}$ & $\begin{array}{c}880^{\mathrm{d}} \\
\pm 9.58\end{array}$ & $\begin{array}{c}3546^{\mathrm{e}} \\
\pm 37.46\end{array}$ & $\begin{array}{c}40^{\mathrm{d}} \\
\pm 0.46\end{array}$ & $\begin{array}{c}51^{\mathrm{c}} \\
\pm 0.53\end{array}$ & $\begin{array}{l}40.90^{\mathrm{d}} \\
\pm 0.94\end{array}$ & $\begin{array}{c}106.48^{\mathrm{d}} \\
\pm 3.64\end{array}$ \\
\hline $\mathrm{T}_{2}$ & $\begin{array}{c}973^{\mathrm{c}} \\
\pm 11.84 \\
1011^{\mathrm{ab}} \\
\pm 10.88\end{array}$ & $\begin{array}{c}4079^{c} \\
\pm 34.35 \\
4178^{b} \\
\pm 28.09\end{array}$ & $\begin{array}{c}44^{\mathrm{c}} \\
\pm 0.56 \\
46^{\mathrm{ab}} \\
\pm 0.52\end{array}$ & $\begin{array}{c}58^{\mathrm{b}} \\
\pm 0.49 \\
59^{\mathrm{ab}} \\
\pm 0.40\end{array}$ & $\begin{array}{l}46.52^{\mathrm{c}} \\
\pm 1.16 \\
50.44^{\mathrm{ab}} \\
\pm 1.15\end{array}$ & $\begin{array}{c}127.53^{\mathrm{b}} \\
\pm 3.01 \\
123.76^{\mathrm{b}} \\
\pm 2.11\end{array}$ \\
\hline $\mathrm{T}_{4}$ & $\begin{array}{r}1034^{\mathrm{a}} \\
\pm 13.58\end{array}$ & $\begin{array}{c}4312^{\mathrm{a}} \\
\pm 37.22\end{array}$ & $\begin{array}{c}47^{\mathrm{a}} \\
\pm 0.65\end{array}$ & $\begin{array}{c}61^{\mathrm{a}} \\
\pm 0.53\end{array}$ & $\begin{array}{l}53.02^{\mathrm{a}} \\
\pm 1.50\end{array}$ & $\begin{array}{c}141.46^{\mathrm{a}} \\
\pm 4.28\end{array}$ \\
\hline $\mathrm{T}_{5}$ & $\begin{array}{r}1043^{\mathrm{a}} \\
\pm 9.57\end{array}$ & $\begin{array}{l}4191^{\mathrm{b}} \\
\pm 66.90\end{array}$ & $\begin{array}{c}47^{\mathrm{a}} \\
\pm 0.45\end{array}$ & $\begin{array}{c}59^{\mathrm{ab}} \\
\pm 0.96\end{array}$ & $\begin{array}{l}57.16^{\mathrm{a}} \\
\pm 1.08\end{array}$ & $\begin{array}{c}130.24^{\mathrm{ab}} \\
\pm 4.81\end{array}$ \\
\hline $\mathrm{T}_{6}$ & $\begin{array}{c}1016^{\mathrm{ab}} \\
\pm 13.16\end{array}$ & $\begin{array}{c}4117^{\mathrm{c}} \\
\pm 69.66\end{array}$ & $\begin{array}{c}46^{\mathrm{ab}} \\
\pm 0.63\end{array}$ & $\begin{array}{c}58^{\mathrm{b}} \\
\pm 0.99\end{array}$ & $\begin{array}{c}50.47^{\mathrm{ab}} \\
\pm 1.39\end{array}$ & $\begin{array}{c}138.01^{\mathrm{ab}} \\
\pm 5.39\end{array}$ \\
\hline $\begin{array}{l}\mathrm{T}_{7} \\
\mathrm{~T}_{8}\end{array}$ & $\begin{array}{c}999^{\mathrm{b}} \\
+11.91 \\
990^{\mathrm{bc}} \\
\pm 12.64 \\
\end{array}$ & $\begin{array}{c}4048^{\mathrm{c}} \\
\pm 46.46 \\
3615^{\mathrm{d}} \\
\pm 35.80 \\
\end{array}$ & $\begin{array}{c}45^{\mathrm{bc}} \\
\pm 0.57 \\
41^{\mathrm{d}} \\
\pm 0.63 \\
\end{array}$ & $\begin{array}{c}57^{\mathrm{b}} \\
\pm 0.66 \\
51^{\mathrm{c}} \\
\pm 0.51 \\
\end{array}$ & $\begin{array}{c}48.54^{\mathrm{b}} \\
\pm 1.21^{1} \mathrm{~b} \\
48.82^{2,3 \mathrm{~b}} \\
\pm 1.49 \\
\end{array}$ & $\begin{array}{c}116.39^{\mathrm{c}} \\
\pm 3.13 \\
126.50^{\mathrm{b}} \\
\pm 4.64 \\
\end{array}$ \\
\hline Sig. & $*$ & $*$ & $*$ & $*$ & $*$ & $*$ \\
\hline
\end{tabular}

\section{Feed intake and feed conversion ratio:}

Data of daily feed intake (FI) and feed conversion ratio (FCR) of Molar ducklings fed graded levels of Proact biweekly and during $0-3$ and $0-10$ weeks are presented in Table (3). Birds fed different levels of probiotics significantly consumed more feed than the control group. Whereas, birds fed Proact level at $1.75 \mathrm{~g} / \mathrm{kg}$ diet consumed significantly less feed than the other Proact groups and nearly equal to the control group at the same periods (79 and 144 vs. 81 and $149 \mathrm{~g} /$ day, respectively).

Feed conversion ratio (FCR) was significantly improved by probiotics supplementation during the experimental period ( $0-10$ weeks of age). From Table 3, it is obvious that inclusion of 0.75 and $1.00 \mathrm{~g}$ Proact/ kg diet improved FCR compared to the control group, being $(1.88,1.75$ vs. 2.05$)$ and $(3.07,3.27$ vs. 3.33 ) at periods of $0-3$ and $0-10$ weeks, respectively.

Ducklings fed Proact level of $1.75 \mathrm{~g} / \mathrm{kg}$ diet proved better FCR compared to the other groups, meanwhile, the control group showed the worst FCR at all periods. The improvement in BW, BWG, FI and FCR of group 4 may be due to the increased efficiency of digestion and nutrient absorption processes in the presence of Proact bacteria.

.Edens (2003) reported that diets supplementation with probiotic allows the development of beneficial bacteria in the digestive tract of the host and improving its performance.

The present findings are in agreement with those of Willis and Reid (2008) and Alkhalf et al. (2010) who observed significant differences in feed consumption and efficiency of broiler chickens receiving probiotic. 
Also, Hassan et al. (2015) noted that total feed intake of ducklings fed $16 \%$ protein diet supplemented with $0.1 \%$ S. cerevisiae is slightly higher than the control birds during the whole experiment.

Table (3): Effect of dietary graded levels of Proact supplementation on feed intake and feed conversion ratio of Molar ducks at 3 and 10 weeks of age (Means \pm S.E).

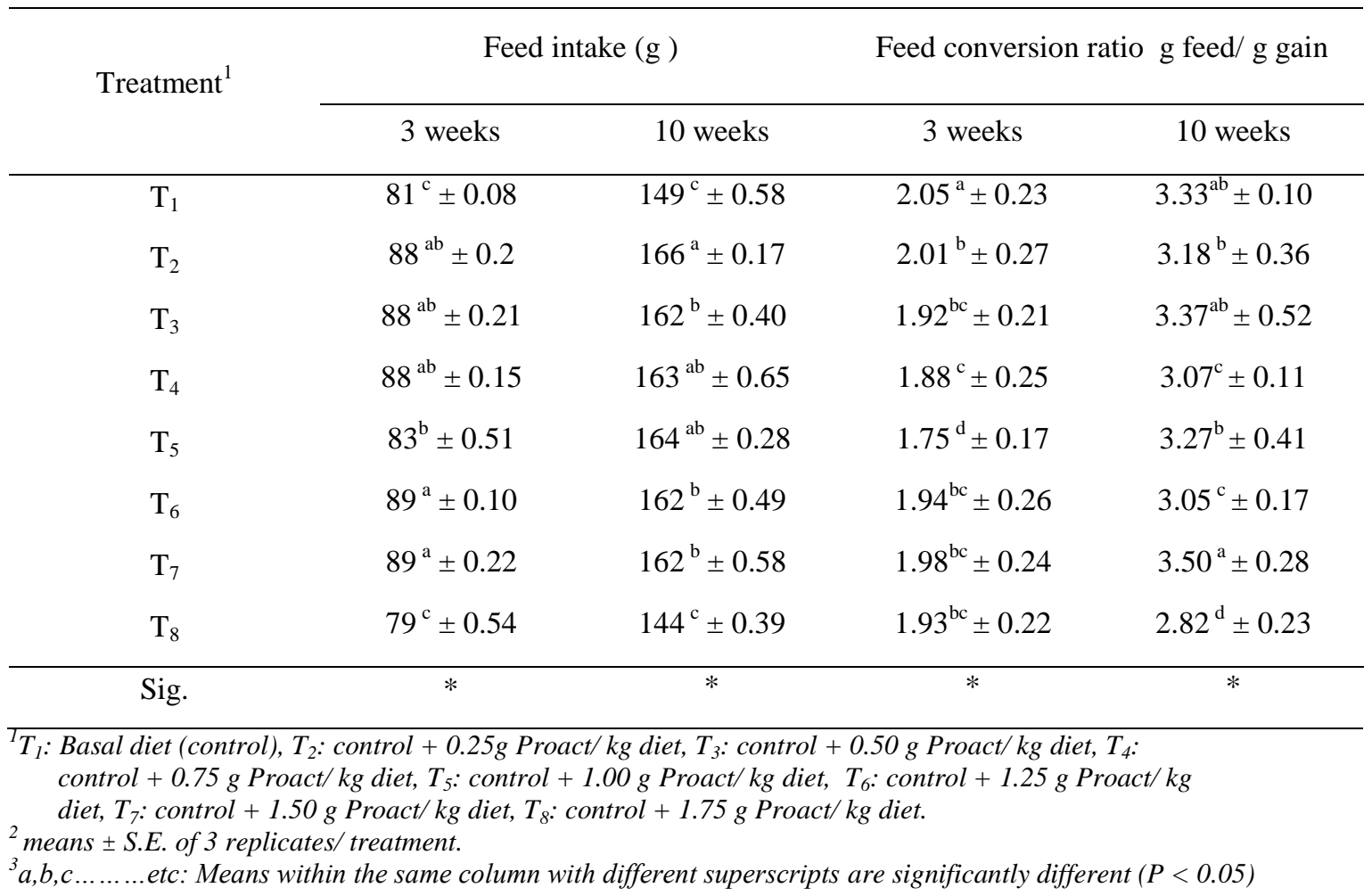

Selvamohan et al. (2012) found that probiotic supplementation led to beneficial production of multiple enzymes including $\alpha$ amylase, $\alpha$ acetolactate decarboxylase, $\beta$ glucanase, malt genic amylase, urease, protease, xylanase, chitinase, phytase, cellulose, hemicellulose and lipase. Bacillus amyloliquefaciens has been found to produce the enzyme $\beta$ mannase (Mabrouk and El-Ahwany, 2008). Production of these enzymes in ducks small intestine would increase their ability to digest and absorb a larger percentage and variety of nutrient in their feed.

In contrast, Zurmiat et al. (2017) indicated that all three doses of B. amyloliquefaciens (1000, 2000 and $3000 \mathrm{ppm} / \mathrm{kg}$ diet) significantly decreased feed consumption compared to the control, besides, feed consumption at 6 weeks old was significantly reduced as the dose of probiotic increased.

\section{Carcass traits:}

Results in Table (4) reveal that the addition of graded levels of probiotics to Molar duckling's diets were significantly affected on some carcass traits (weights and percentages). Ducklings received 0.75g Proact/ kg diet acquired the highest carcass weight (3041g) and giblets weight (341g) compared to the control group (2627 and $248 \mathrm{~g}$, respectively). This indicates that this feed additive has a positive impact on carcass traits.

These results are in agreement with the results of Hascik et al. (2009) who conducted that there is statistically significant influence of the supplementation of probiotic on carcass traits of broiler chickens. In contrast, our results are opposite to the results of Weis and Hrncar (2013) and Hassan et al. (2015) who reported that there was no significant difference in all carcass traits due to probiotics supplementation. 


\section{Serum blood parameters:}

Supplementation of graded levels of probiotics showed no significant differences in the concentration of serum total protein, albumen and activity of ALT enzyme (Table 5). However, adding different levels of probiotics significantly increased both serum glucose and activity of AST enzyme, whereas, significantly reduced serum createnine, cholesterol, triglycerides and total lipids compared to the control group.

Our results are in agreement with those of Hassan et al. (2015) who reported that probiotics did not significantly affect serum total protein level. However, Joy and Samual (1997) stated that adding probiotic to broiler diets significantly decreased serum cholesterol. Also, Mohan et al. (1996) proved that probiotic exhibited lipid lowering properties which might be related to the interference of probiotic bacteria with cholesterol absorption in the gut by conjugating bile salts or directly assimilating cholesterol.

However, Panda et al. (2006) stated that concentration of serum protein significantly increased due to probiotic supplementation. While, Djouvinov et al. (2005) reported that serum cholesterol was not significantly affected by feeding probiotic preparation to mule ducklings.

Table (4): Effect of dietary graded levels of Proact supplementation on some carcass traits of Molar ducks at 10 weeks of age (Means \pm S. E).

\begin{tabular}{|c|c|c|c|c|c|c|c|}
\hline Treatments $^{1}$ & LBW $(g)^{4}$ & $\begin{array}{c}\text { Carcass } \\
\text { weight } \\
(\mathrm{g})^{5}\end{array}$ & $\begin{array}{c}\text { Dressing } \\
(\%)^{6}\end{array}$ & $\begin{array}{c}\text { Giblets } \\
\text { weight }(\mathrm{g})\end{array}$ & $\begin{array}{c}\text { Liver } \\
(\%)\end{array}$ & $\begin{array}{c}\text { Heart } \\
(\%)\end{array}$ & $\begin{array}{c}\text { Gizzard } \\
(\%)\end{array}$ \\
\hline $\mathrm{T}_{1}$ & $\begin{array}{c}3641^{\mathrm{b}} \\
\pm 45.50\end{array}$ & $\begin{array}{l}2627^{\mathrm{b}} \\
\pm 42.00\end{array}$ & $\begin{array}{r}72.15 \\
\pm 0.42\end{array}$ & $\begin{array}{l}248^{\mathrm{d}} \\
\pm 3.50\end{array}$ & $\begin{array}{l}3.52^{c} \\
\pm 0.11\end{array}$ & $\begin{array}{l}1.07^{\mathrm{b}} \\
\pm 0.03\end{array}$ & $\begin{array}{c}2.23^{2,3 a} \\
\pm 0.18\end{array}$ \\
\hline $\mathrm{T}_{2}$ & $\begin{array}{l}4009^{\mathrm{a}} \\
\pm 42.20\end{array}$ & $\begin{array}{c}2862^{\mathrm{a}} \\
\pm 18.00\end{array}$ & $\begin{array}{r}71.39 \\
\pm 1.13\end{array}$ & $\begin{array}{l}298^{\mathrm{bc}} \\
\pm 3.50\end{array}$ & $\begin{array}{c}4.47^{\mathrm{b}} \\
\pm 0.19\end{array}$ & $\begin{array}{l}1.00^{\mathrm{bc}} \\
\pm 0.10\end{array}$ & $\begin{array}{l}1.97^{\mathrm{bc}} \\
\pm 0.29\end{array}$ \\
\hline $\mathrm{T}_{3}$ & $\begin{array}{l}4105^{\mathrm{a}} \\
\pm 24.00\end{array}$ & $\begin{array}{c}2930^{\mathrm{a}} \\
\pm 13.00\end{array}$ & $\begin{array}{r}71.38 \\
\pm 1.53\end{array}$ & $\begin{array}{l}298^{\mathrm{bc}} \\
\pm 3.00\end{array}$ & $\begin{array}{c}4.41^{\mathrm{b}} \\
\pm 0.01\end{array}$ & $\begin{array}{l}0.99^{\mathrm{bc}} \\
\pm 0.21\end{array}$ & $\begin{array}{l}1.86^{\mathrm{c}} \\
\pm 0.22\end{array}$ \\
\hline $\mathrm{T}_{4}$ & $\begin{array}{l}4154^{\mathrm{a}} \\
\pm 30.00\end{array}$ & $\begin{array}{l}3041^{\mathrm{a}} \\
\pm 28.50\end{array}$ & $\begin{array}{l}73.21 \\
\pm 1.21\end{array}$ & $\begin{array}{l}341^{\mathrm{a}} \\
\pm 1.00\end{array}$ & $\begin{array}{l}4.77^{\mathrm{a}} \\
\pm 0.01\end{array}$ & $\begin{array}{l}1.34^{\mathrm{a}} \\
\pm 0.70\end{array}$ & $\begin{array}{l}2.11^{\mathrm{ab}} \\
\pm 0.21\end{array}$ \\
\hline $\mathrm{T}_{5}$ & $\begin{array}{l}4059^{\mathrm{a}} \\
\pm 24.00\end{array}$ & $\begin{array}{c}2938^{\mathrm{a}} \\
\pm 20.00\end{array}$ & $\begin{array}{l}72.38 \\
\pm 1.96\end{array}$ & $\begin{array}{l}304^{\mathrm{b}} \\
\pm 0.50\end{array}$ & $\begin{array}{l}4.24^{b} \\
\pm 0.11\end{array}$ & $\begin{array}{l}1.20^{\mathrm{ab}} \\
\pm 0.18\end{array}$ & $\begin{array}{l}2.06^{\mathrm{abc}} \\
\pm 0.54\end{array}$ \\
\hline $\mathrm{T}_{6}$ & $\begin{array}{l}4039^{\mathrm{a}} \\
\pm 20.50\end{array}$ & $\begin{array}{c}2856^{\mathrm{a}} \\
\pm 14.00\end{array}$ & $\begin{array}{l}70.71 \\
\pm 0.70\end{array}$ & $\begin{array}{l}306^{\mathrm{b}} \\
\pm 3.50\end{array}$ & $\begin{array}{c}4.26^{\mathrm{b}} \pm \\
0.05\end{array}$ & $\begin{array}{l}1.18^{\mathrm{ab}} \\
\pm 0.90\end{array}$ & $\begin{array}{l}2.15^{\mathrm{ab}} \\
\pm 0.27\end{array}$ \\
\hline $\mathrm{T}_{7}$ & $\begin{array}{c}3993^{\mathrm{a}} \\
\pm 22.00\end{array}$ & $\begin{array}{c}2874^{\mathrm{a}} \\
\pm 16.00\end{array}$ & $\begin{array}{r}71.98 \\
\pm 1.33\end{array}$ & $\begin{array}{l}301^{\mathrm{bc}} \\
\pm 6.00\end{array}$ & $\begin{array}{l}4.28^{b} \\
\pm 0.20\end{array}$ & $\begin{array}{l}1.05^{\mathrm{bc}} \\
\pm 0.10\end{array}$ & $\begin{array}{l}2.20^{\mathrm{a}} \\
\pm 0.30\end{array}$ \\
\hline $\mathrm{T}_{8}$ & $\begin{array}{l}3967^{2,3 a} \\
\pm 16.00\end{array}$ & $\begin{array}{l}2870^{\mathrm{a}} \\
\pm 12.00\end{array}$ & $\begin{array}{r}72.35 \\
\pm 0.23\end{array}$ & $\begin{array}{l}290^{\mathrm{c}} \\
\pm 2.00\end{array}$ & $\begin{array}{l}4.33^{\mathrm{b}} \\
\pm 0.04\end{array}$ & $\begin{array}{l}0.94^{c} \\
\pm 0.17\end{array}$ & $\begin{array}{l}2.02^{\mathrm{abc}} \\
\pm 0.51\end{array}$ \\
\hline Sig. & $*$ & $*$ & N.S. & $*$ & $*$ & $*$ & $*$ \\
\hline \multicolumn{8}{|c|}{$\begin{array}{l}{ }^{1} T_{1}: \text { Basal diet (control), } T_{2}: \text { control }+0.25 \mathrm{~g} \text { Proact/ } \mathrm{kg} \text { diet, } T_{3}: \text { control }+0.50 \mathrm{~g} \text { Proact/ } \mathrm{kg} \text { diet, } T_{4}: \text { control }+ \\
\quad 0.75 \mathrm{~g} \text { Proact/ } \mathrm{kg} \text { diet, } T_{5}: \text { control }+1.00 \mathrm{~g} \text { Proact/ } \mathrm{kg} \text { diet, } T_{6}: \text { control }+1.25 \mathrm{~g} \text { Proact/ } \mathrm{kg} \text { diet }, T_{7}: \text { control }+ \\
\quad 1.50 \mathrm{~g} \text { Proact/ } \mathrm{kg} \text { diet, } T_{8}: \text { control }+1.75 \mathrm{~g} \text { Proact/ } \mathrm{kg} \text { diet. } \\
{ }^{2} \text { means } \pm \text { S.E. of } 3 \text { replicates/ treatment. } \\
{ }^{3} \text { a,b,c........etc: Means within the same column with different superscripts are significantly different }(P<0.05) \text {. } \\
{ }^{4} \mathrm{LBW}=\text { Live Body weight. }{ }^{5} \text { Carcass weight }(\mathrm{g}) \text { without giblets. }{ }^{6} \text { dressing }(\%) \text { was calculated relative to live } \\
\text { body weight. }\end{array}$} \\
\hline
\end{tabular}

\section{Intestinal morphological parameters:}

Data concerning morphological parameters are presented in Table (6) and Figures (1, 2 and 3). The results reveal that villi height, villi width and villi height : villi width ratio were significantly increased progressively with probiotics supplementation levels up to $1.25 \mathrm{~g} / \mathrm{kg}$ diet and thereafter, tended to decrease, but still better than the control. 
Except for jejunum villi width, duodenum villi height and width of chicks fed diets supplemented with $1.25 \mathrm{~g}$ probiotics/ $\mathrm{kg}$ diet were 34.05 and $82.65 \%$ higher than the control in comparison with the other levels and was $76.61 \%$ in the jejunum villi height for the same group. On the other side, ducklings fed $1 \mathrm{~g}$ probiotics/ $\mathrm{kg}$ diet had the highest jejunum villi width percent $(59.31 \%)$ and the best ileum villi height and width percent (61.95 and $52.38 \%$ ) compared to the control and the other treatments.

Table (5): Effect of dietary graded levels of Proact supplementation on some serum blood parameters of Molar ducks at 10 weeks of age (Means \pm S. E).

\begin{tabular}{|c|c|c|c|c|c|c|c|c|c|}
\hline \multirow{2}{*}{$\operatorname{Trt}^{1}$} & $\mathrm{TP}$ & Alb. & Cr. & Chol. & Glu. & TG & TP & AST & ALT \\
\hline & \multicolumn{2}{|c|}{--------g/dl--------- } & \multicolumn{5}{|c|}{----------------------------- mg/dl ----------------------------- } & \multicolumn{2}{|c|}{------ U/L ------ } \\
\hline \multirow{2}{*}{$\mathrm{T}_{1}$} & 2.75 & 1.40 & $0.36^{\mathrm{a}}$ & $180.30^{\mathrm{a}}$ & $5.38^{\mathrm{b}}$ & $146.50^{\mathrm{a}}$ & $553.89^{\mathrm{a}} \pm$ & $30.10^{2,3}$ & 22.15 \\
\hline & \pm 0.64 & \pm 0.10 & \pm 0.06 & \pm 10.70 & \pm 0.88 & \pm 14.50 & 37.41 & ${ }^{\mathrm{c}} \pm 1.32$ & \pm 2.82 \\
\hline \multirow{2}{*}{$\mathrm{T}_{2}$} & 2.87 & 1.69 & $0.23^{\mathrm{b}}$ & $122.45^{\mathrm{d}}$ & $6.32^{\mathrm{ab}}$ & $126.60^{\mathrm{ab}}$ & $386.66^{b}$ & $42.40^{\mathrm{a}}$ & 29.39 \\
\hline & \pm 0.01 & \pm 0.32 & \pm 0.08 & \pm 15.45 & \pm 1.33 & \pm 10.60 & \pm 45.15 & \pm 7.10 & \pm 11.79 \\
\hline \multirow{2}{*}{$\mathrm{T}_{3}$} & 2.98 & 1.65 & $0.24^{\mathrm{b}}$ & $135.55^{\mathrm{c}}$ & $7.90^{\mathrm{ab}}$ & $121.50^{\mathrm{b}}$ & $444.20^{b}$ & $40.55^{\mathrm{a}}$ & 20.25 \\
\hline & \pm 0.40 & \pm 0.13 & \pm 0.01 & \pm 1.45 & \pm 0.10 & \pm 1.50 & \pm 4.84 & \pm 0.10 & \pm 2.650 \\
\hline \multirow[b]{2}{*}{$\mathrm{T}_{4}$} & 3.15 & 1.54 & $0.28^{\mathrm{b}}$ & $147^{\mathrm{c}}$ & $11.79^{\mathrm{a}}$ & $119.50^{\mathrm{ab}}$ & $453.81^{\mathrm{ab}}$ & $40.42^{\mathrm{a}}$ & 17.53 \\
\hline & \pm 0.52 & \pm 0.07 & \pm 0.03 & \pm 10.00 & \pm 4.35 & \pm 8.50 & \pm 31.21 & \pm 3.29 & \pm 1.93 \\
\hline \multirow{2}{*}{$\mathrm{T}_{5}$} & 3.13 & 1.50 & $0.31^{\mathrm{b}}$ & $146.85^{c}$ & $7.29^{\mathrm{ab}}$ & $121.50^{\mathrm{b}}$ & $445.93^{b}$ & $42.50^{\mathrm{a}}$ & 73.90 \\
\hline & \pm 0.23 & \pm 0.09 & \pm 0.05 & \pm 0.85 & \pm 0.52 & \pm 4.50 & \pm 2.57 & \pm 5.40 & \pm 7.70 \\
\hline \multirow[b]{2}{*}{$\mathrm{T}_{6}$} & 2.96 & 1.66 & $0.27^{\mathrm{b}}$ & $154.55^{b c}$ & $7.07^{\mathrm{ab}}$ & $120.55^{\mathrm{ab}}$ & $470.69^{\mathrm{ab}}$ & $39.72^{\mathrm{ab}}$ & 24.75 \\
\hline & \pm 0.58 & \pm 0.14 & \pm 0.02 & \pm 9.55 & \pm 1.23 & \pm 4.45 & \pm 24.92 & \pm 4.42 & \pm 3.55 \\
\hline \multirow{2}{*}{$\mathrm{T}_{7}$} & 2.91 & 1.59 & $0.29^{b}$ & $154.90^{\mathrm{bc}}$ & $6.39^{\mathrm{ab}}$ & $117.80^{\mathrm{ab}}$ & $469.95^{\mathrm{ab}}$ & $37.80^{\mathrm{ab}}$ & 25.33 \\
\hline & \pm 0.44 & \pm 0.04 & \pm 0.08 & \pm 16.20 & \pm 1.04 & \pm 10.80 & \pm 47.68 & \pm 7.70 & \pm 8.27 \\
\hline \multirow{2}{*}{$\mathrm{T}_{8}$} & 2.89 & 1.82 & $0.29^{b}$ & $168.85^{b}$ & $6.05^{\mathrm{ab}}$ & $98.50^{b}$ & $391.39^{b}$ & $41.20^{\mathrm{a}}$ & 23 \\
\hline & \pm 0.29 & \pm 0.05 & \pm 0.08 & \pm 1.85 & \pm 0.27 & \pm 3.50 & \pm 7.47 & \pm 0.60 & \pm 1.30 \\
\hline Sig. & N.S & N.S & * & $*$ & $*$ & $*$ & $*$ & * & N.S \\
\hline \multicolumn{10}{|c|}{ 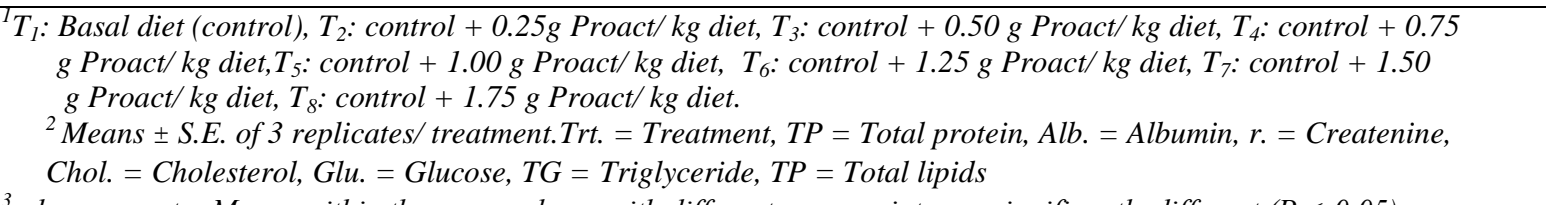 } \\
\hline \multicolumn{10}{|c|}{ 3a,b,c.......etc: Means within the same column with different superscripts are significantly different $(P<0.05)$} \\
\hline
\end{tabular}


Table (6): Effect of dietary graded levels of Proact supplementation on intestinal sections morphology of Molar ducks at 10 weeks of age (Means \pm S. E).

\begin{tabular}{|c|c|c|c|c|c|c|c|c|c|}
\hline \multirow{2}{*}{ 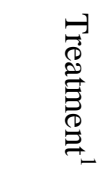 } & \multicolumn{3}{|c|}{ Duodenum villi $(\mu \mathrm{m})$} & \multicolumn{3}{|c|}{ Jejunum villi $(\mu \mathrm{m})$} & \multicolumn{3}{|c|}{ Ileum villi $(\mu \mathrm{m})$} \\
\hline & $\begin{array}{c}\text { Height, } \\
\text { H }\end{array}$ & $\begin{array}{l}\text { Width, } \\
\text { W }\end{array}$ & $\mathrm{H} / \mathrm{W}$ & $\begin{array}{c}\text { Height, } \\
\text { H }\end{array}$ & $\begin{array}{l}\text { Width, } \\
\text { W }\end{array}$ & $\mathrm{H} / \mathrm{W}$ & $\begin{array}{c}\text { Height, } \\
\text { H }\end{array}$ & $\begin{array}{l}\text { Width, } \\
\text { W }\end{array}$ & $\mathrm{H} / \mathrm{W}$ \\
\hline $\mathrm{T}_{1}$ & $\begin{array}{l}1304^{\mathrm{e}} \\
\pm 6.73\end{array}$ & $\begin{array}{c}98^{c} \\
\pm 4.86\end{array}$ & $\begin{array}{l}13.34^{\mathrm{c}} \\
\pm 0.61\end{array}$ & $\begin{array}{c}915^{\mathrm{e}} \\
\pm 7.02\end{array}$ & $\begin{array}{l}145^{\mathrm{c}} \\
\pm 2.65\end{array}$ & $\begin{array}{c}6.31^{\mathrm{b}} \\
\pm 0.18\end{array}$ & $\begin{array}{c}728^{\mathrm{d}} \\
\pm 7.21\end{array}$ & $\begin{array}{c}126^{\mathrm{d}} \\
\pm 3.65\end{array}$ & $\begin{array}{c}5.76^{2,3 \mathrm{bcd}} \\
\pm 0.21\end{array}$ \\
\hline $\mathrm{T}_{2}$ & $\begin{array}{l}1420^{\mathrm{d}} \\
\pm 5.59\end{array}$ & $\begin{array}{l}100 \mathrm{c} \\
\pm 5.99\end{array}$ & $\begin{array}{l}14.23^{\mathrm{b}} \\
\pm 0.66\end{array}$ & $\begin{array}{l}1140^{\mathrm{d}} \\
\pm 9.57\end{array}$ & $\begin{array}{c}167^{\mathrm{b}} \\
\pm 3.70\end{array}$ & $\begin{array}{c}6.85^{\mathrm{b}} \\
\pm 0.19\end{array}$ & $\begin{array}{c}852^{c} \\
\pm 9.97\end{array}$ & $\begin{array}{c}137^{\mathrm{cd}} \\
\pm 4.20\end{array}$ & $\begin{array}{l}6.23^{\mathrm{ab}} \\
\pm 0.19\end{array}$ \\
\hline $\mathrm{T}_{3}$ & $\begin{array}{l}1504^{\mathrm{cd}} \\
\pm 6.63\end{array}$ & $\begin{array}{c}137^{\mathrm{b}} \\
\pm 3.57\end{array}$ & $\begin{array}{l}10.99^{\mathrm{d}} \\
\pm 0.35\end{array}$ & $\begin{array}{c}1229^{c} \\
\pm 11.63\end{array}$ & $\begin{array}{c}180^{\mathrm{b}} \\
\pm 7.36\end{array}$ & $\begin{array}{c}6.83^{\mathrm{b}} \\
\pm 0.17\end{array}$ & $\begin{array}{c}860^{c} \\
\pm 8.88\end{array}$ & $\begin{array}{c}151^{\mathrm{c}} \\
\pm 5.31\end{array}$ & $\begin{array}{l}5.70^{\mathrm{bc}} \\
\pm 0.15\end{array}$ \\
\hline $\mathrm{T}_{4}$ & $\begin{array}{l}1590^{c} \\
\pm 5.02\end{array}$ & $\begin{array}{c}163^{\mathrm{a}} \\
\pm 8.29\end{array}$ & $\begin{array}{c}9.76^{\mathrm{d}} \\
\pm 0.27\end{array}$ & $\begin{array}{l}1396^{\mathrm{b}} \\
\pm 5.55\end{array}$ & $\begin{array}{c}220^{\mathrm{a}} \\
\pm 6.75\end{array}$ & $\begin{array}{c}6.35^{\mathrm{b}} \\
\pm 0.12\end{array}$ & $\begin{array}{l}1159^{\mathrm{a}} \\
\pm 6.65\end{array}$ & $\begin{array}{c}171^{\mathrm{b}} \\
\pm 6.60\end{array}$ & $\begin{array}{c}6.78^{\mathrm{a}} \\
\pm 0.16\end{array}$ \\
\hline $\mathrm{T}_{5}$ & $\begin{array}{l}1649^{b} \\
\pm 3.73\end{array}$ & $\begin{array}{c}171^{\mathrm{a}} \\
\pm 7.84\end{array}$ & $\begin{array}{c}9.65^{\mathrm{d}} \\
\pm 0.25\end{array}$ & $\begin{array}{l}1545^{\mathrm{a}} \\
\pm 4.06\end{array}$ & $\begin{array}{c}231^{\mathrm{a}} \\
\pm 2.70\end{array}$ & $\begin{array}{c}6.65^{\mathrm{b}} \\
\pm 0.12\end{array}$ & $\begin{array}{l}1179^{\mathrm{a}} \\
\pm 4.45\end{array}$ & $\begin{array}{c}192^{\mathrm{a}} \\
\pm 3.80\end{array}$ & $\begin{array}{l}5.15^{\text {bcd }} \\
\pm 0.19\end{array}$ \\
\hline $\mathrm{T}_{6}$ & $\begin{array}{l}1748^{\mathrm{a}} \\
\pm 2.44\end{array}$ & $\begin{array}{c}179^{\mathrm{a}} \\
\pm 3.39\end{array}$ & $\begin{array}{c}9.77^{\mathrm{d}} \\
\pm 0.30\end{array}$ & $\begin{array}{r}1616^{\mathrm{a}} \\
\pm 5.87\end{array}$ & $\begin{array}{l}150^{\mathrm{c}} \\
\pm 3.95\end{array}$ & $\begin{array}{l}10.82^{\mathrm{a}} \\
\pm 0.38\end{array}$ & $\begin{array}{l}1112^{\mathrm{ab}} \\
\pm 6.10\end{array}$ & $\begin{array}{l}180^{\mathrm{ab}} \\
\pm 5.65\end{array}$ & $\begin{array}{l}5.63^{\mathrm{cd}} \\
\pm 0.13\end{array}$ \\
\hline $\mathrm{T}_{7}$ & $\begin{array}{l}1664^{\mathrm{b}} \\
\pm 4.36\end{array}$ & $\begin{array}{c}110^{\mathrm{c}} \\
\pm 8.61\end{array}$ & $\begin{array}{l}15.13^{\mathrm{a}} \\
\pm 0.89\end{array}$ & $\begin{array}{l}1485^{b} \\
\pm 6.49\end{array}$ & $\begin{array}{c}136^{\mathrm{c}} \\
\pm 9.96\end{array}$ & $\begin{array}{l}10.93^{\mathrm{a}} \\
\pm 0.37\end{array}$ & $\begin{array}{c}950^{\mathrm{b}} \\
\pm 7.97\end{array}$ & $\begin{array}{l}175^{\mathrm{ab}} \\
\pm 6.15\end{array}$ & $\begin{array}{c}5.43^{\mathrm{d}} \\
\pm 0.16\end{array}$ \\
\hline $\mathrm{T}_{8}$ & $\begin{array}{l}1580^{\mathrm{c}} \\
\pm 8.81\end{array}$ & $\begin{array}{c}99^{c} \\
\pm 7.45\end{array}$ & $\begin{array}{l}15.99^{a} \\
\pm 0.75\end{array}$ & $\begin{array}{r}1287^{\mathrm{c}} \\
\pm 7.45\end{array}$ & $\begin{array}{c}115^{\mathrm{d}} \\
\pm 7.25\end{array}$ & $\begin{array}{l}11.26^{\mathrm{a}} \\
\pm 0.50\end{array}$ & $\begin{array}{c}875^{\mathrm{c}} \\
\pm 4.50\end{array}$ & $\begin{array}{c}141^{\mathrm{cd}} \\
\pm 3.70\end{array}$ & $\begin{array}{l}6.23^{\mathrm{ab}} \\
\pm 0.11\end{array}$ \\
\hline Sig. & $*$ & $*$ & * & $*$ & $*$ & $*$ & $*$ & $*$ & $*$ \\
\hline 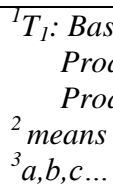 & $\begin{array}{l}\text { (control) } \\
\text { diet, } T_{5}: c\end{array}$ & the & $25 g$ & $\begin{array}{l}\text { kg di } \\
\text { iet, } \quad T_{6} \\
\text { liet. }\end{array}$ & cont & $50 \mathrm{~g}$ & $\mathrm{ct} / \mathrm{kgc}$ & 4: con & $\begin{array}{l}+0.75 g \\
0 g\end{array}$ \\
\hline
\end{tabular}



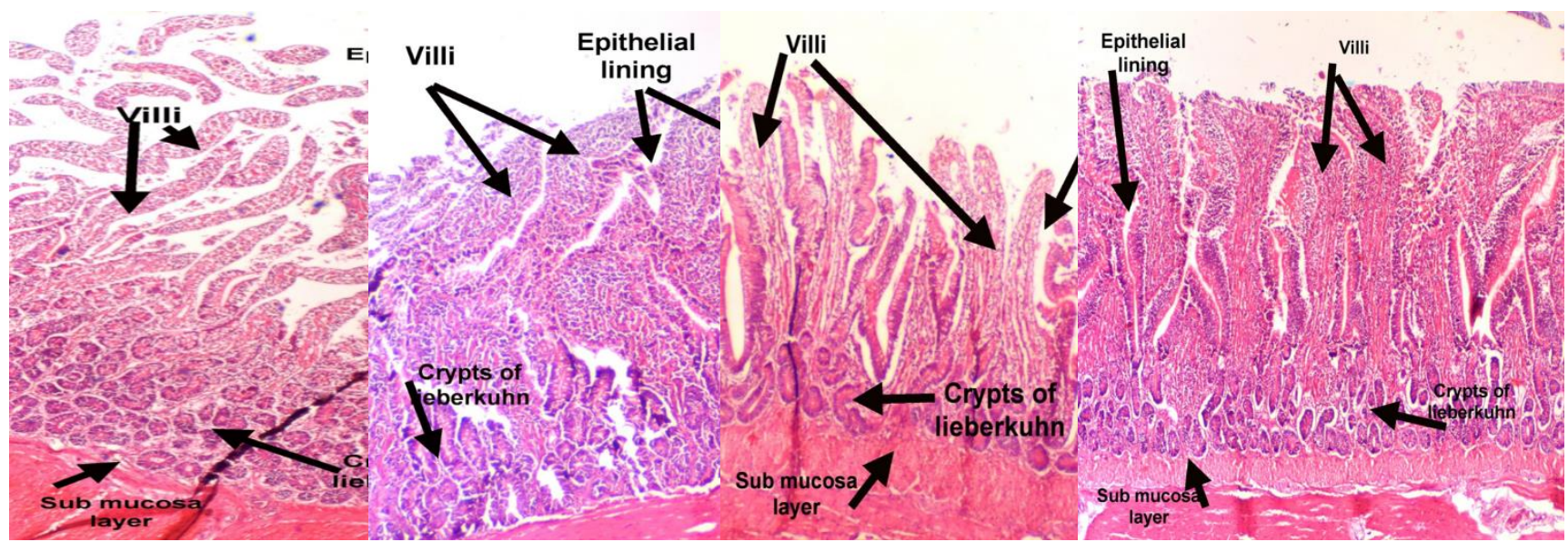

Control group, $\mathrm{T}_{1}$

$\mathrm{T}_{2}, 0.25 \mathrm{~g}$ Proact / kg diet

T3, 0.50g Proact / kg

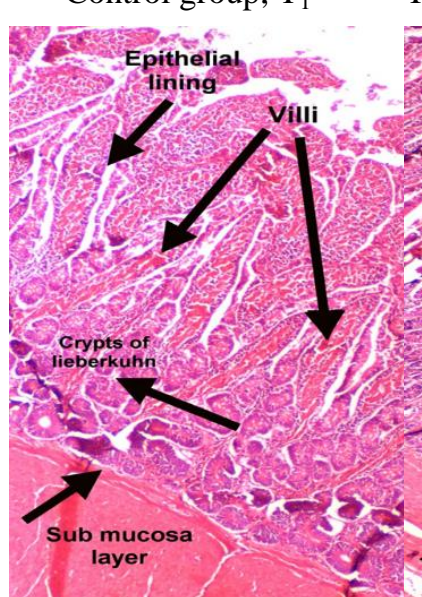

T3, 0.50g Proac

T4, 0.75g Proact / kg

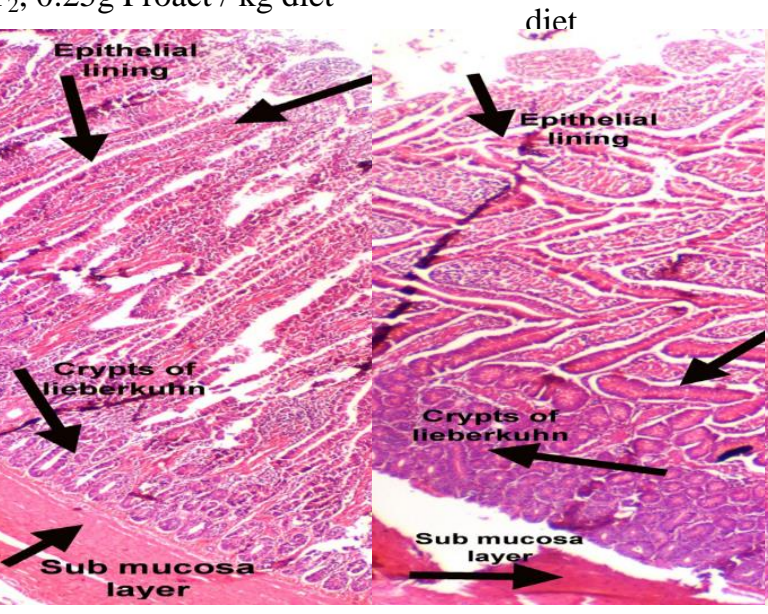

$\mathrm{T}_{5}, 1 \mathrm{~g}$ Proact / kg diet

T6, 1.25g Proact / kg diet
T7, 1.50g Proact / kg diet

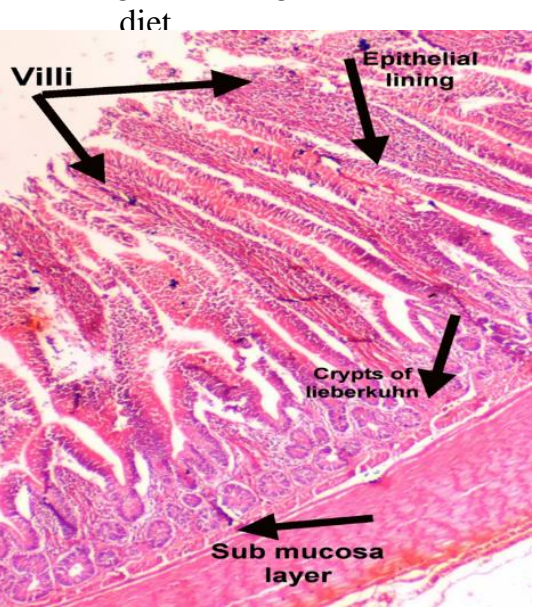

T8, 1.75g Proact / kg diet

Figure (1): Effect of dietary graded levels of Proact supplementation on intestinal Duodenum section of Molar ducks at 10 weeks of age. 

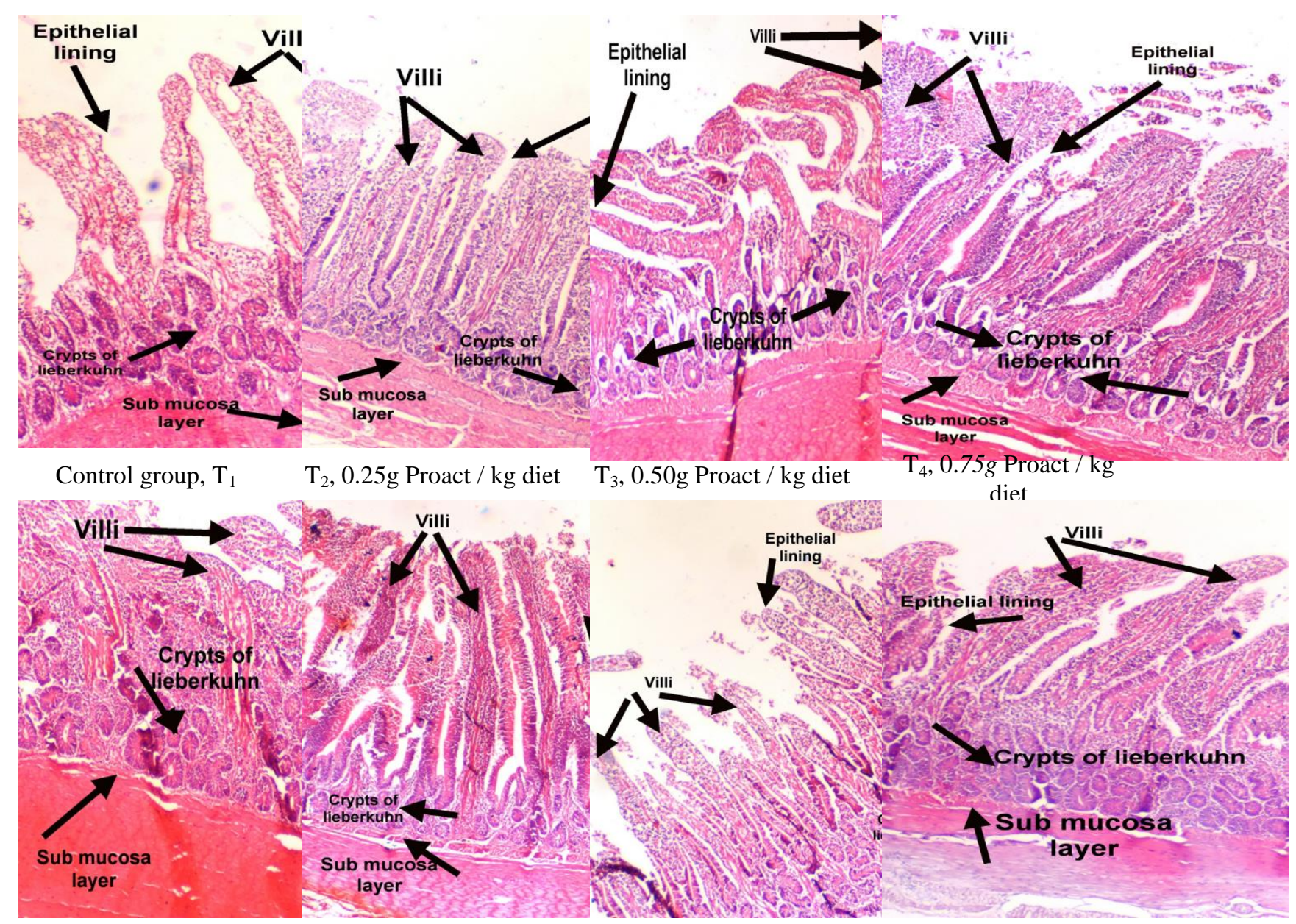

$\mathrm{T}_{5}, 1 \mathrm{~g}$ Proact $/ \mathrm{kg}$ diet $\quad \mathrm{T}_{6}, 1.25 \mathrm{~g}$ Proact $/ \mathrm{kg}$ diet $\quad \mathrm{T}_{7} 1.50 \mathrm{~g}$ Proact $/ \mathrm{kg} \operatorname{diet} \quad \underset{\text { diet }}{\mathrm{T}_{8}, 1.75 \mathrm{~g} \text { Proact } / \mathrm{kg}}$

Figure (2): Effect of dietary graded levels of Proact supplementation on intestinal Jejunum section of Molar ducks at 10 weeks of age.

It is understood that greater villus height is an indicator that the function of intestinal villi is activated (Shamoto and Yamauchi, 2000). This fact suggests that the villus function is activated after feeding of dietary probiotic. Moreover, increased passive absorption of glucose and proline was reported in broiler chickens fed a probiotic containing lactobacilli, B. thermophilum, and E. faecium (Chichlowski et al., 2007).

The histomorphological changes in the intestine of ducklings in the present study provide new information regarding the potential for using probiotics in their diets. Increasing the villus height suggests an increased surface area capable of greater absorption of available nutrients (Caspary, 1992). A shortening of the villi and deeper crypts may lead to poor nutrient absorption, increased secretion in the gastrointestinal tract, and lower performance (Xu et al., 2003).

The villus crypt is considered as the villus factory and deeper crypts indicate fast tissue turnover to permit renewal of the villus as needed in response to normal sloughing or inflammation from pathogens or their toxins and high demands for tissue (Anonymous, 1999). 

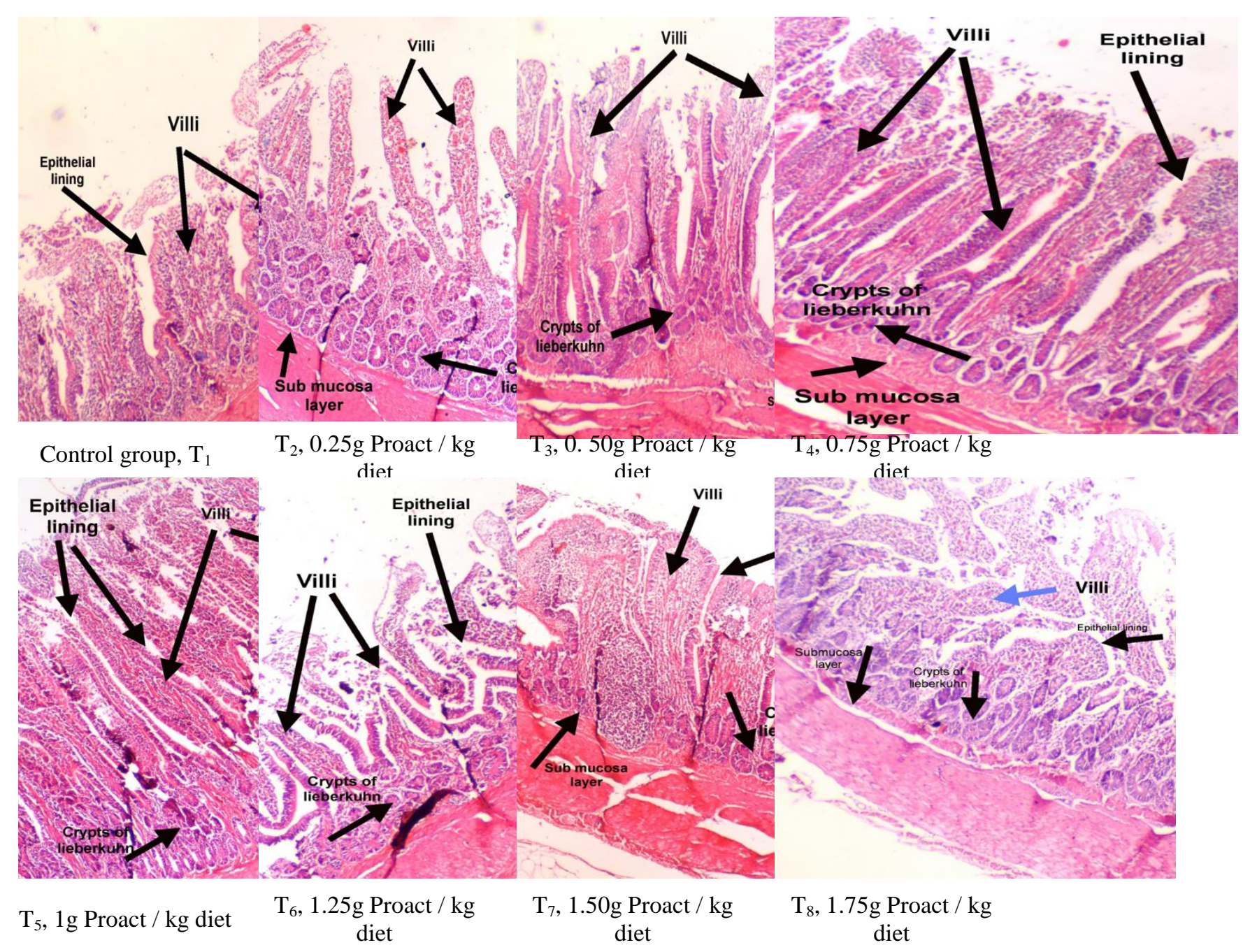

Figure (3): Effect of dietary graded levels of Proact supplementation on intestinal Ileum section of Molar ducks at 10 weeks of age.

Our results are in synergism with the findings of Chichlowski et al. (2007) who found that addition of probiotic containing lactobacilli, B. thermophilum, and E. faecium to the broiler diet increased the jejunal villus height. Longer villi were found in the ileum of chicks and turkeys treated with Lactobacillus reuteri (Dunham et al., 1993) and in the ileum of adult male layers with slight improvement in feed efficiency after dietary addition of Bacillus subtilis (Samanya and Yamauchi, 2002).

In addition, longer villi were induced by dietary amylase (Ritz et al., 1995). The concentrations of amylase in broiler intestine were increased after supplementation of diet with either a single strain of Lactobacillus acidophilus or a mixture of Lactobacillus strains (Jin et al., 2000). It is assumed that an increased villus height is paralleled by an increased digestive and absorptive function of the intestine due to increased absorptive surface area, expression of brush border enzymes, and nutrient transport systems (Pluske et al., 1996).

\section{Economic efficiency:}

Results of feeding cost for ducks fed the experimental diets are presented in Table (7). The relative economic efficiency measures the difference between the income of the business and the cost of the feed and is a product of meat production and marketing price. Production volume is influenced by feed price, feed intake, final body weight, mortality and marketing price. Through our inputs and outcomes for 10 weeks old Molar ducklings, relative economic efficiency was increased with the addition of probiotics up to $0.75 \mathrm{~g} / \mathrm{kg}$ diet $(\mathrm{REF}=112 \%)$, and net revenue $=95.82$ L.E. compared to 75.22 L.E. for the un - supplemented group. 
Also, European efficiency index confirms these results and ducklings of group 4 had 201 compared to 150 for the control group.

Table (7): Effect of dietary graded levels of Proact supplementation on the economic efficiency of the experimental diets at 70 days of age.

\begin{tabular}{|c|c|c|c|c|c|c|c|c|}
\hline \multirow{2}{*}{ Item } & \multicolumn{8}{|c|}{ Dietary treatment $^{1}$} \\
\hline & $\mathrm{T}_{1}$ & $\mathrm{~T}_{2}$ & $\mathrm{~T}_{3}$ & $\mathrm{~T}_{4}$ & $\mathrm{~T}_{5}$ & $\mathrm{~T}_{6}$ & $\mathrm{~T}_{7}$ & $\mathrm{~T}_{8}$ \\
\hline Initial body weight, g. & 47.70 & 47.60 & 47.63 & 47.63 & 47.73 & 47.80 & 47.70 & 47.77 \\
\hline Final body weight, kg. & 3.55 & 4.08 & 4.18 & 4.31 & 4.19 & 4.12 & 4.05 & 3.62 \\
\hline Body weight gain, kg. & 3.50 & 4.03 & 4.13 & 4.26 & 4.14 & 4.07 & 4.00 & 3.57 \\
\hline $\begin{array}{l}\text { Total revenue }{ }^{2} . \text { L. E. } \\
\text { Feed intake, kg. }\end{array}$ & $\begin{array}{c}133 \\
10.43\end{array}$ & $\begin{array}{c}153 \\
11.62\end{array}$ & $\begin{array}{c}157 \\
11.34\end{array}$ & $\begin{array}{c}162 \\
11.41\end{array}$ & $\begin{array}{c}157 \\
11.48\end{array}$ & $\begin{array}{c}155 \\
11.34\end{array}$ & $\begin{array}{c}152 \\
11.34\end{array}$ & $\begin{array}{c}136 \\
10.08\end{array}$ \\
\hline Price of one $\mathrm{kg}$ feed, L. E. & 5.54 & 5.62 & 5.71 & 5.79 & 5.88 & 5.96 & 6.04 & 6.13 \\
\hline Feed cost, L. E. & 57.78 & 65.30 & 64.75 & 66.06 & 67.50 & 67.59 & 68.49 & 61.97 \\
\hline Net revenue $^{3}$, L. E. & 75.22 & 87.84 & 92.19 & 95.82 & 89.82 & 87.07 & 83.51 & 73.76 \\
\hline Economical efficiency ${ }^{4}$. & 1.30 & 1.35 & 1.42 & 1.45 & 1.33 & 1.29 & 1.22 & 1.19 \\
\hline $\begin{array}{l}\text { Relative economic } \\
\text { efficiency, } \% \text {. }\end{array}$ & 100 & 104 & 109 & 112 & 102 & 99 & 94 & 92 \\
\hline European efficiency index ${ }^{5}$. & 152 & 183 & 177 & 201 & 183 & 193 & 165 & 183 \\
\hline \multicolumn{9}{|c|}{$\begin{array}{l}{ }^{1} T_{1}: \text { Basal diet (control), } T_{2}: \text { control }+0.25 \mathrm{~g} \text { Proact/ } \mathrm{kg} \text { diet, } T_{3}: \text { control }+0.50 \mathrm{~g} \text { Proact/ } \mathrm{kg} \text { diet, } T_{4}: \text { control }+ \\
0.75 \mathrm{~g} \text { Proact } \mathrm{kg} \text { diet }, T_{5}: \text { control }+1.00 \mathrm{~g} \text { Proact } \mathrm{kg} \text { diet, } T_{6}: \text { control }+1.25 \mathrm{~g} \text { Proact } / \mathrm{kg} \text { diet }, T_{7}: \text { control }+ \\
1.50 \mathrm{~g} \text { Proact } \mathrm{kg} \text { diet, } T_{8}: \text { control }+1.75 \mathrm{~g} \text { Proact/ } \mathrm{kg} \text { diet. }\end{array}$} \\
\hline $\begin{array}{l}\text { Price of one kg live body weigh } \\
{ }^{2} \text { Total revenue }=\text { live body weig } \\
{ }^{3} \text { Net revenue }=\text { Total revenue }- \\
{ }^{4} \text { Economical efficiency }=\text { Net re } \\
{ }^{5} \text { European efficiency index, EEI } \\
\text { ratio) } \times 100 \text {. }\end{array}$ & $\begin{array}{l}38 \text { L.E. } \\
\text { in } \times \text { mar } \\
\text { cost. } \\
\text { e / Feed } \\
\text { lean hod }\end{array}$ & eting pric & rice of or & $D_{2}$ & 337 & O L.E. & & \\
\hline
\end{tabular}

\section{CONCLUSION}

The obtained results indicate that supplementation of $0.75 \mathrm{~g}$ probiotic (Proact) $/ \mathrm{kg}$ diet can be used in diets of Molar ducklings from 0-10 weeks of age to improve performance, feed efficiency, and economic efficiency.

\section{REFERENCES}

Alkhalf, A., M. Alhaj and I. Al-homidan (2010). Influence of probiotic supplementation on blood parameters and growth performance in broiler chickens. Saudi. Poult. Sci., 17, 219 - 225.

Anonymous (1999). How do mannan oligosaccharides work? Feed. Times 1: 7 - 9.

Awad, W. A., K. Ghareeb, S. Abdel-Raheem and J. Böhm, (2009). Effects of dietary inclusion of probiotic and synbiotic on growth performance, organ weights, and intestinal histomorphology of broiler chickens. Poult. Sci., 88:49 - 56.

Caspary, W.F. (1992). Physiology and pathophysiology of intestinal absorption. The American J. of Clinical Nutr. 55, 299 - 308. 
Chichlowski, M., J. Croom, B.W. McBride, L. Daniel, G. Davis and M.D. Koci (2007). Direct-fed Microbial primalac and salinomycin modulate whole-body and intestinal oxygen consumption and intestinal mucosal cytokine production in the broiler chick. Poult. Sci., 86: 1100 -1106.

Djouvinov, D., S. Boicheva, T. Simeonova and T. Vlaikova (2005). Effect of feeding lactina probiotic on performance, some blood parameters and cecal microflora of multi ducklings. Trakia Journal of Sciences, Vol. 3, (2), $22-28$.

Duncan, D. B. (1955). Multiple range and multiple F tests. Biometrics, 11:1- 42.

Dunham, H. J., C. Williams, F. W. Edens, I. A. Casas and W.J. Dobrogosz (1993). Lactobacillus reuteri immunomodulation of stressor-associated diseases in newly hatched chickens and turkeys. Poult. Sci., 72(Suppl. 1):103. (Abstr).

Edens F.W. (2003). An alternative for antibiotic use in poultry probiotics. Brazilian Journal of Poultry Science. 2003;5: $75-97$.

Hascik P, M. Kacaniova, I. Novakova, M. Fikselova, V. Kulisek,

K. Vavrisinova and H. Arpasova (2009). Effect of probiotics on protein production in fattening chicken meat. Slovak J. Anim. Sci., 42: 22 - 26.

Heady, E. O. and H. R. Jensen (1954). Farm Management Economics. Pentice - Hall Inc. Englewood Cliffs, N.J., USA.

Hernandez-Mendoza, A., H. S. Garcia and J. L. Steele (2009). Screening of Lactobacillus casei strains for their ability to bind aflatoxin B1. Food Chem. Toxicol. 47:1064 - 1068.

Hemarajata, P. and J. Versalovic (2012). Effects of probiotics on gut microbiota: Mechanisms of intestinal immunomodulation and neuromodulation. Ther. Adv. Gastroent. 0:1-13.

Jin, L. Z., H. W. Ho, N. Abdullah and S. Jalaludin (2000). Digestive and bacteria enzyme activities in broilers fed diets supplemented with Lactobacillus cultures. Poult. Sci., 79: 886 -891.

Joy A. D. and J.J. Samual (1997). Effect of probiotic supplementation on the performance of broiler. J. of Vet. and Anim. Sci., 28(1): 10 - 14.

Kabir, S. M. L., M. M. Rahman, M. B. Rahman, M. M. Rahman and S. U. Ahmed (2004). The dynamics of probiotics on growth performance and immune response in broilers. Int. J. Poult. Sci. 3:361 - 364.

Koenen, M. E., J. Kramer, R. Van Der Hulst, L. Heres, S. H. M.

Jeurissen and W. J. A. Boersma (2004). Immunomodulation by probiotic lactobacilli in layer- and meat-type chickens. Br. Poult. Sci. 45:355 - 366.

Mohan, B., R. Kadirvel, M. Natarajan and M. Bhaskaran (1996). Effect of probiotic supplementation on growth, nitrogen utilization and serum cholesterol in broilers. Brit. Poult. Sci., 37, 395 - 401.

Mabrouk E. M. M. and A. M. D. El Ahwany (2008). Production of $\beta$-mannanase by Bacillus amylolequifaciens 10A1 cultured on potato peels. African Journal of Biotechnology Vol. 7 (8): 1123 1128.

Mountzouris, K. C., P. Tsistsikos, E. Kalamara, S. Nitsh, G. Schatzmayr and K. Fegeros (2007). Evaluation of the efficacy of a probiotic containing Lactobacillus, Bifidobacterium, Enterococcus, and Pediococcus strains in promoting broiler performance and modualting cecal microflora composition and metabolic activities. Poult. Sci. 86:309 - 317.

North, M. O. (1981). Commercial chicken production manual. $3^{\text {rd }}$ Ed., The AVI, Publishing Co. Inc., Westport, Connecticut, U. S. A.

NRC (1994). Nutrient requirements of poultry. 9th rev. ed. Washington (DC): National Academy Press.

Panda, A. K., S. V. R. Rao, M. V. Raju and S. R. Sharma (2006). Dietary supplementation of Lactobacillus sporogenes on performance and serum biochemico-lipid profile of broiler chickens. Poult. Sci., 43, 235 240. 
Pascual, M., M. Hugas, J. I. Badiola, J. M. Monfort and M.Garriga (1999). Lactobacillus salivarius CTC2197 prevents Salmonella Enteritidis colonization in chickens. Appl. Environ. Microbiol. 65: 49814986.

Peng, Q., X. Zeng, J. Zhu, S. Wang, X. Liu, C. Hou, P. Thacker and

S. Qiao (2016). Effects of dietary Lactobacillus plantarum B1 on growth performance, intestinal microbiota, and short chain fatty acid profiles in broiler chickens. Poult. Sci. 95:893 - 900.

Pluske, J. R., M. J. Tompson, C. S. Atwood, P. H. Bird, I. H. Williams and P. E. Hartmann (1996). Maintenance of villus height and crypt depth, and enhancement of disaccharide digestion and monosaccharide absorption, in piglets fed on cows' whole milk after weaning. Br. J. Nutr. 76:409 - 422.

Hassan, I.M. H., M.M. Gamal, M. Abdelstar and M. Abd-Ellah (2015).

Effect of feeding probiotic on performance of broiler ducks fed different protein levels. J. of Adv. Vet. Res. Vol. 5, (3): 136 - 142.

Ritz, C. W., R. M. Hulet, B. B. Self and D. M. Denbow (1995). Growth and intestinal morphology of male turkeys as influenced by dietary supplementation of amylase and xylanase. Poult. Sci., 74:1329 - 1334.

Samanya, M. and K. Yamauchi (2002). Histological alterations of intestinal villi in chickens fed dried subtilis var.natto. Comparative Biochemistry and Physiology. 133. 95 - 104.

Selvamohan T., V. Ramadas and S. Sh. S. Kishore (2012). Antimicrobial activity of selected medicinal plants against some selected human pathogenic bacteria. Adv. in Appl. Sci., Res. 3 (5): 3374 - 3381.

Shamoto, K. and K. Yamauchi (2000). Recovery responses of chick intestinal villus morphology to different re-feeding procedures. Poult. Sci., 79: 718-723.

Snedecor, W. G. and G. W. Cochran (1982). Statistical methods. (6 ${ }^{\text {th }}$ ed.). Iowa State College Press. Iowa, USA.

Soltan, M. E. and Z. Kusainova (2012). Performance of broiler chickens in different farming with different feed conversion under Egyptian conditions. Minufiya J. Agric. Res. V., 37 No. 5 (1): 1155 - 1159.

SPSS (2011). SPSS 11.0 for Windows. SPSS Inc., Chicago. Standardization ministration of China. 2005. National feed Industry Standards for Enzyme Assays in China.

Thomas, Sh. K., A. Jalaudeen, D. Rajendran and P. N. Richard Jagatheesan (2015). Influence of dietary supplementation of probiotic on body weight of white Peking ducks. Indian Vet. J., 92 (12): 34- 36.

Weis, J. and C. Hrnčár (2013). Effect of probiotic supplementation on performance of different broiler genotypes. Anim. Welfare, Ethology and Housing system. Vol. 9 (3): 626 - 632.

Wills, W. L. and L. Reid (2008). Investigating the effects of dietary probiotic feeding regimens on broiler chicken production and Campylobacter jejuni presence. Poult. Sci., Vol. 87, p. 606 - 611.

Xu, Z. R., C. H. Hu, M. S. Xia, X. A. Zhan and M. Q. Wang (2003). Effects of dietary fructo oligosaccharide on digestive enzyme activities, intestinal microflora and morphology of male broilers. Poult. Sci., 82:1030 - 1036.

Zurmiati, W., M. H. Abbas, E. M. Maria and F. Revan (2017). Effect of bacillus amyloliquefaciens as a probiotic on growth performance parameters of Pitalah ducks. Inter. J. of Poult. Sci., ISSN: 147- 153. 


\title{
تأثير إضافة مستويات متدرجة من البروبيوتيك على كفاءة النمو ومكونات الدم والتغير الههنولوجى للأمعاء فى صغار البط المولر
}

\author{
منال كمال أبو النجا1 ، عاطف محم حسن أبو عاشور 1 ، سيد عبد الفتاح عبد الرحمن و على جابر بيومى2

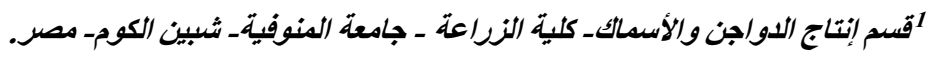 \\ 2 الب دراسات عليا (ماجستير).
}

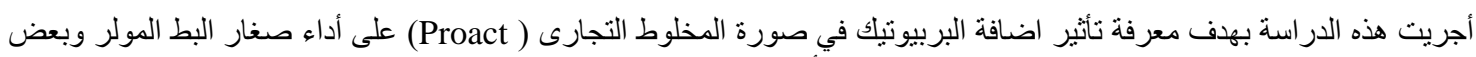

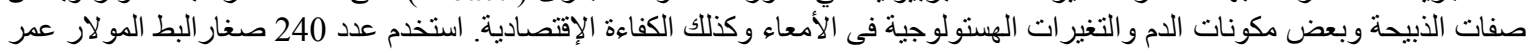

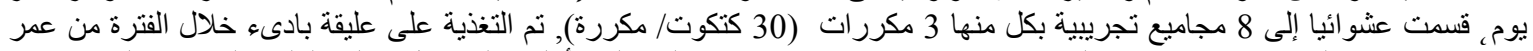

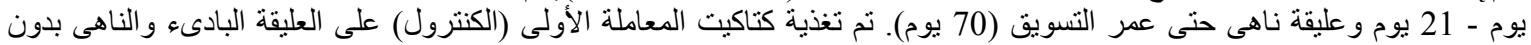

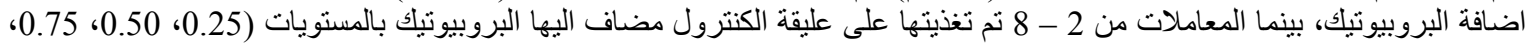

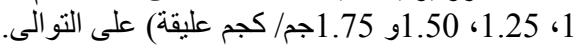

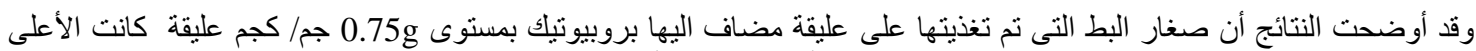

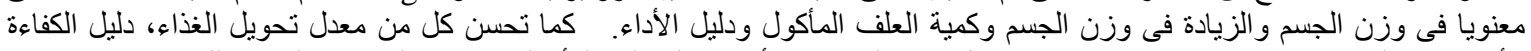

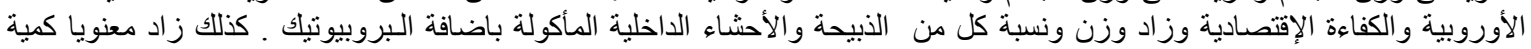

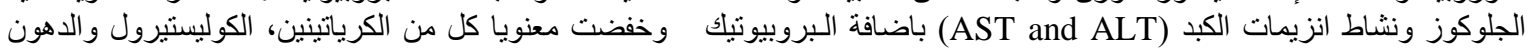

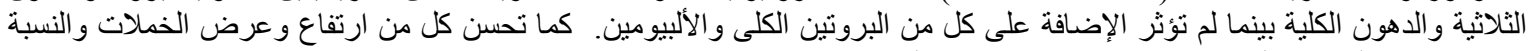
بينهما بإضافة البروبيوتيك بمستوى 0.75g جم/ كجم عليقة.

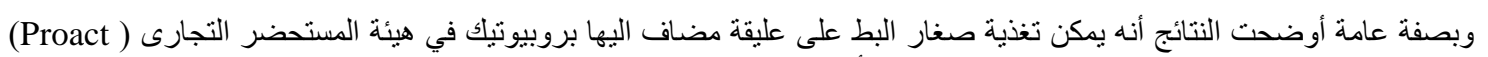

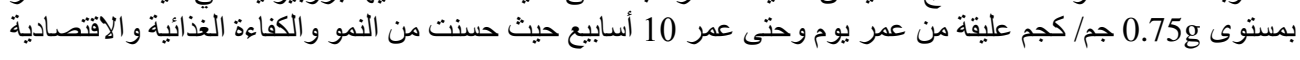

